\title{
4th International Conference on Materials in Jordan: Jordanian Life Sciences for Sustainable Development (JLSSD)
}

\author{
April 27 29th 2017 \\ Al al-Bayt University, Mafraq, Jordan
}

Previously organized, International Conferences/Humboldt Kollegs and workshops, were held between 2008 2011. Workshops have dealt with Archaeology, Water or Astronomy while the two conferences in 2009 and 2011 dealt with materials in Jordan. The 3rd Int. Conf. in 2014 dealt with "Building Int. Networks for Enhancement of Research in Jordan".

Although these conferences met had the German Jordanian University (GJU) as the only academic institution took part in the organization of the first Conference in 2009. Ten universities and institutions were involved in the organization of the conference in 2011, which reflects the wide interest in the activities which the Jordanian Club of Humboldt Fellows (JCHF) organizes. Patronage of these Kollegs ranged from Prime Minister to Ministers of Higher Education and Scientific research and to the Minister of Energy and Mineral Resources.

The Conf. in 2014 titled "Research Enhancement in Jordan" and the role of networks in this effect was held with contributions from various research topics ranging from, chemistry, physics, pharmacy, humanities, arts, medicine and archaeology.

Her Royal highness (HRH) Princess Sumaya Bint El Hassan, president of the El Hassan Science City, Chairman of the Royal Scientific Society, patronized the Conf. providing her vision at the importance of networks to enhance research. Minister of Higher Education and Scientific Research introduced how best to invest in Int. cooperation.

This 4th Int. Conf. held between April 27 29th, 2017 "Jordanian Life Sciences for Sustainable Development" was held at Al al-Bayt University in Mafraq under HRH Princess Sumaya Bint El Hassan. Nobel Prize winner the German scientist Professor "Erwin Neher" from the Max Planck Institute for Biophysical Chemistry, Goettingen, was the main invited Keynote speaker who gave a talk titled "Ion Channels: their discovery, their function, and their role in disease." That lecture was attended by about three hundred Professors, students and specialists.

Opening talks were given by: Prof. Marwan S. Mousa, President of JCHF, Ambassador of Germany HE Brigitta Siefker-Eberle, Prof. Hani Hayajneh, Ambassador Scientist of Alexander von Humboldt Foiundation (AvH), Chairman of the Conf. Prof.. Dia Eddin Arafah, president of AABU. This was closed by the talk of Minister Mohammad Hamdan representing HRH Princess Sumaya Bint El Hassan.

Present in the Conf. were top scientists, Chairmen of the AvH Associations in MENA region and Europe, Dr. Jaime Sperberg, first Sec. and head of Cultural Dept. of the German Embassy in Jordan, Gabrielle von Fircks the Director of DAAD in Jordan, Katharina Schmidt Director of German Protestant Institute of Archaeology, Dr. Rene Klaff head of Regional office of Friederich Naumann Foundation for MENA.

Workshops on various topics related to life sciences were held. Young scientists participated at two days pre-Conf. training workshop, chaired by Prof. Dr. Hans Limbach from FU/Berlin and involved eleven postgraduate students from six MENA countries (Syria, Egypt, Tunis, Algeria, Gaza and Jordan).

All these Conferences were supported by the Science Research Support Fund in Jordan and the AvH.

Tours after the Conference were organized to enable participants to visit Universities, research institutions in addition to visiting main historic sites of Jordan.

Marwan S. Mousa

Department of Physics, Mu'tah University, Al-Karak 61710, Jordan

(a) This is an open-access article distributed under the terms of the Creative Commons Attribution Non-Commercial License (http://creativecommons.org/licenses/by-nc/4.0) which permits unrestricted noncommercial use, distribution, and reproduction in any medium, provided the original work is properly cited.

Copyrights @ 2017 by Korean Society of Microscopy 